\title{
Trading system of environmental loads: interregional cap and trade system using an ecological footprint
}

\author{
T. Ujihara ${ }^{1} \&$ M. Taniguchi ${ }^{2}$ \\ ${ }^{1}$ Graduate School of Environmental Science, Okayama University, Japan \\ ${ }^{2}$ Graduate School of Systems and Information Engineering, \\ University of Tsukuba, Japan
}

\begin{abstract}
National lands are classifiable by their usage into source areas and sink areas. Urban areas are environmentally dependent on the land use of rural areas. The concept of environmental balance provides a key perspective. Urban and regional planning including land use planning based on that concept can address environmental problems comprehensively. In recent years, based on the concept of the environmental balance, Ujihara et al. proposed an interregional trading system of environmental loading using ecological footprint. The system is designed to conduct interregional trading based on urban and regional planning. By providing incentives, the system is anticipated as a mode of securing financial resources to promote measures for improvement of the environmental balance voluntarily. However, to consider introduction of the system specifically, it is necessary to examine whether the system provides a structure to improve the environmental balance from the perspective of securing financial resources for urban and regional planning. This study proposed a mechanism for securing financial resources based on an interregional cap and trade system using $\mathrm{EF}$. The study explored future prospects of the system to examine effects on financial resources for urban and regional planning. Results of those analyses show that trading prices related with interregional cap and trade systems using EF are highly influential for financial resources intended for urban and regional planning. The case study demonstrated the possibility that implementation costs are covered by the trading price, even if large-scale measures that drastically reform the regional structure are implemented.
\end{abstract}

Keywords: cap and trade system, ecological footprint, urban planning. 


\section{Introduction}

In recent years, the international and interregional emissions trading of environmental loads has been implemented as a countermeasure against worsening global warming. Typical emissions trading systems are international emissions trading established under the Kyoto Protocol and the EU-ETS being conducted in EU countries. The intended environmental loads of those systems are restricted to greenhouse gases because the systems have been conducted specifically to mitigate global warming. However, global environmental problems became diversified. It is necessary to implement measures from a broad perspective to address those other problems as well as greenhouse gases.

National lands are classifiable by their usage into source areas (carbon dioxide emissions and food consumption in urban areas) and sink areas (nature absorbs environmental loads in rural areas). Urban areas are environmentally dependent on the land use of rural areas. The concept of environmental balance provides a key perspective. Urban and regional planning including land use planning based on that concept can address environmental problems comprehensively. In fact, the Panel on Infrastructure Development, held under the auspices of the Ministry of Land, Infrastructure, Transport and Tourism in Japan, first described the structure for realizing effective utilization of urban areas and preservation of the natural environment in suburban areas by trading of mutual land use [1].

The Ecological Footprint (EF) developed by Wackernagel and Rees has attracted worldwide attention over the years [2]. The EF can represent different environmental loads such as carbon dioxide emissions and food consumption comprehensively on an areal basis. Moreover, this indicator can represent the intra-regional relation between environmental capacity (forests, farmland, etc.) and environmental loading. It enables estimation of the environmental balance from the viewpoint of limited earth resources. In recent years, based on the concept of the environmental balance, Ujihara et al. [3] proposed an interregional trading system of environmental loading using EF. The system is designed to conduct interregional trading based on urban and regional planning. By providing incentives, the system is anticipated as a mode of securing financial resources to promote measures for improvement of the environmental balance voluntarily. The system is being discussed as an efficient tool for growth strategies in the Panel on Infrastructure Development described above. It is a breakthrough move that raises the feasibility of this system. However, to consider introduction of the system specifically, it is necessary to examine whether the system provides a structure to improve the environmental balance from the perspective of securing financial resources for urban and regional planning.

This report of our study explains an interregional cap and trade system using EF developed by Ujihara et al. [3]; it proposes a structure to improve the environmental balance based on the system. Based on the structure, the study explores future prospects of the system to examine the effect on financial resources for urban and regional planning. 


\subsection{Previous studies}

The EF indicator was developed by Wackernagel and Rees in the early 1990s [3]. The indicator has been calculated at various scales such as national [3-6] and regional levels [7-11]. Moreover, means to improve the EF value have been studied from the standpoint of urban and regional planning [12-16].

The EF can reveal land areas that depend on other regions by comparing the environmental capacity in a country or region. Andersson and Lindroth [17] quantitatively described land resource dependency of trade using EF. They examined issues in trade from a sustainability standpoint.

Recently, specifically regarding land resource dependency, Cap and Trade systems using EF have been developed by Ujihara et al. [3] and Ohl et al. [18]. The system developed by Ohl et al. [18] is designed to trade international environmental loads constituting differences from the global average of environmental capacity (1.8 gha per person). The awareness of the problems is the same as that of the system developed by Ujihara et al. [3], but the system developed by Ohl et al. [18] is not designed as an approach toward the improvement of environmental balance in regions based on urban and regional planning.

\subsection{Interregional cap and trade system using EF}

This section explains the interregional cap and trade system using EF developed by Ujihara et al. [3]. The explanation presents a framework that is useful for establishing national land use for a balanced environment.

\subsubsection{What is the interregional cap and trade system using an ecological footprint?}

Table 1 presents the contents of the interregional cap and trade system using an Ecological Footprint.

\subsubsection{Framework toward national land use for a balanced environment}

Based on an interregional cap and trade system using the EF indicator, this chapter presents a new framework intended for national land use for a balanced environment. Figure 1 portrays the framework.

1) First, the EF is introduced into the master plan for deciding the future guidelines for land use. The use of EF enables the local government to reassess land use in a region based on the environmental balance.

2) Second, based on results of 1), the local government discusses and implements land-use measures such as Urban Compaction and Land Recycling, for improving the environmental balance. Both 1) and 2) shall establish a foundation for participation in an interregional cap and trade system at the national level without the need for new calculations of environmental loads.

3) Finally, "Interregional Cap and Trade" must build a banking system for managing necessary information such as the environmental load excess ratio " $r$ " 
Table 1: $\quad$ Contents of the interregional cap and trade system using an EF [3].

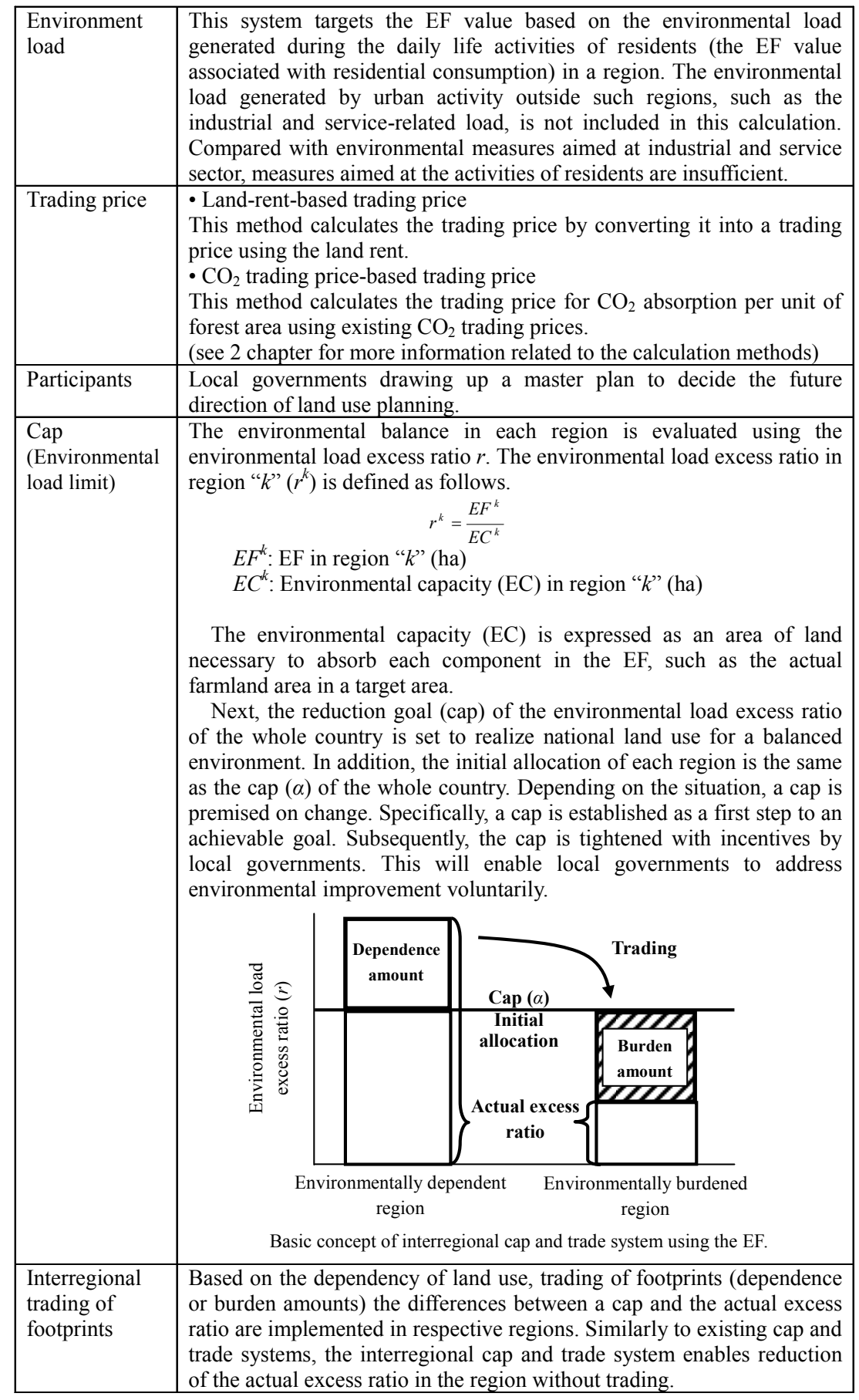


and the situation of measures in various regions. This banking systemenables interregional trading of footprints in national areas. Furthermore, a cap - the Limit of Environmental Load Excess Ratio " $r$ "- is established as a first step to an achievable goal. The cap is subsequently tightened using incentives for local governments.

Through repetition of 2) and 3) using a long-term perspective, the framework was intended to form environmentally balanced regions and national lands (" $\alpha$ "> "r" (1.0)).

This framework will enable local governments to address environmental improvement voluntarily through urban and regional planning.

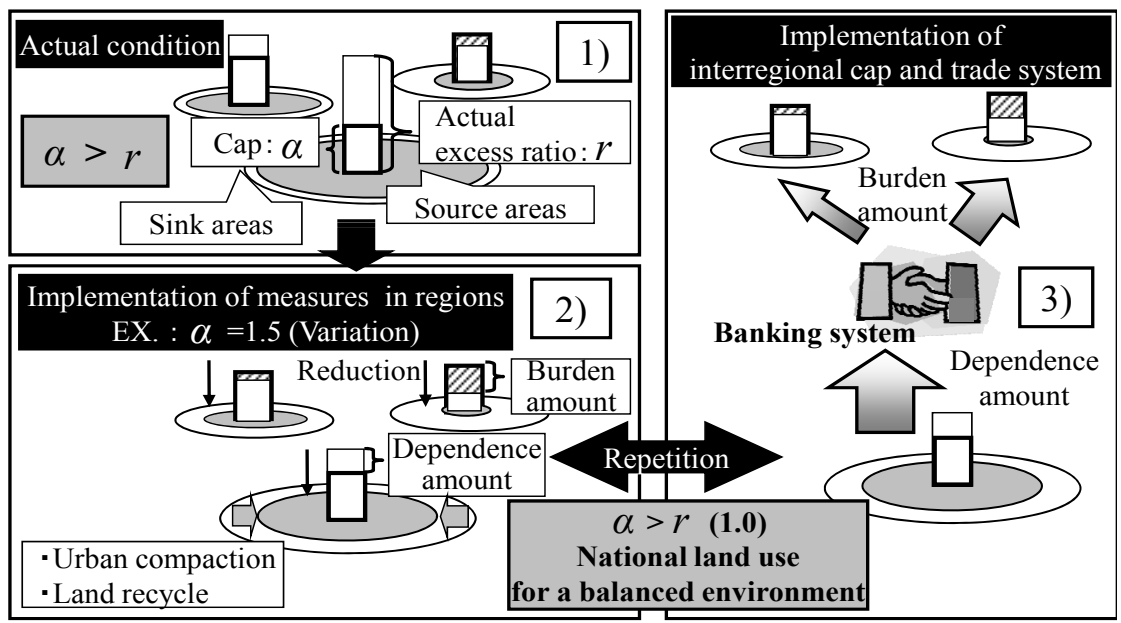

Figure 1: $\quad$ Framework toward national land use for a balanced environment [3].

\section{Methods}

As discussed in chapter 1, the cap and trade system developed by Ujihara et al. [3] is designed to conduct interregional trading based on urban and regional planning. It can be expected to serve as a mode of securing revenues to promote voluntary measures toward improvement of the environmental balance.

Then, the system is discussed as an efficient tool for a growth strategy at the Panel on Infrastructure Development [1]. The basis of discussion is a desire to introduce the concept of the system for a growth strategy, even if the urban area side bears trading costs of the dependence amount. These are breakthroughs that indicate the feasibility of the system that must provide full understanding and agreement with the urban area side.

Although a larger movement exists at the national level, the system presents challenges such as setting of the cap and the association between trading prices that are determined based on the cap and financial resources for urban and regional planning. 
This chapter presents the structure of securing revenues for urban and regional planning based on the interregional cap and trade system using the EF, verifies following matter based on the structure. Figure 2 presents the structure.

1) The standard-setting of cap (initial allocation) is defined. The trading price (financial resources) obtained by trading the burden amount is also clarified.

2) Various ways exist to use the financial resources. However, if measures to improve the environmental balance will be implemented, then the trading system generates new financial resources through improvement in a region. This creates incentives to implement measures in a region.

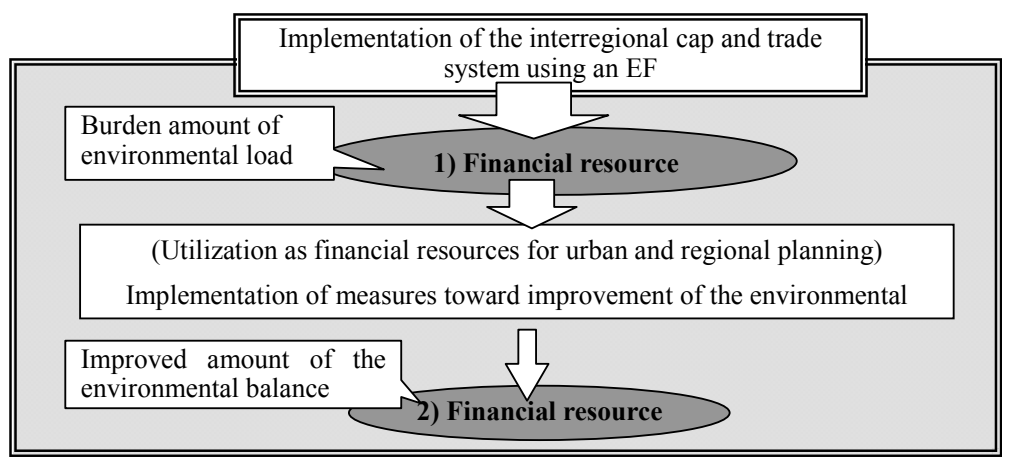

Figure 2: Mechanism for securing financial resource based on interregional cap and trade system using EF.

On the assumption that a trading price is used as a financial resource for the urban and regional planning that engender improve environmental balance, this chapter presents a comparison of trading prices and implementation costs based on scenario analysis. Furthermore, the case study quantifies the trading price (financial resources) generated through measures, showing how much those financial resources to investment amount in the case of utilization trading price obtained as the environmental burden amount of the environmental load.

\subsection{Prerequisite for case study}

\subsubsection{Setting the cap}

For an interregional cap and trade system using EF, trading prices vary according to the cap. The case study sets the standard of the cap and calculates the trading price based on it. From the standpoint of ecological debt based on land-resource dependency, trading prices are clarified as an environmental burden (or dependence) amount of the environmental load. Assuming interregional trading on a nationwide scale, the standard of caps is subject to the following equation.

$$
\sum_{j=1}^{n} E P_{j}^{d}=\sum_{k=1}^{m} E P_{k}^{b}
$$

$E P_{j}^{d}$ : Trading price of Environmentally dependent region " $j$ " $E P_{k}^{b}$ : Trading price of Environmentally burdened region " $k$ " 
The cap is set such that the total trading price of environmentally dependent regions becomes equivalent to that of an environmentally burdened region. In other words, it is necessary to set an environmental load excess ratio based on the EF and EC values of the whole country as the initial cap. Lowering the cap over the long term is the ultimate aim at national land use for a balanced environment; the environmental load excess ratio is " 1.0 ".

\subsubsection{Calculation of EF}

This case study calculates the EF value based on the environmental load generated during the daily life activities of residents (the EF value associated with residents' consumption) in a region. Consequently, the environmental load generated by urban activity outside such regions, such as the industrial and service-related load, is not included in this calculation. The reasons are the following: 1) The calculable objects and scale are limited, because it is a necessity to consider Input-Output analysis. 2) Insufficient measures are aimed at the activities of residents compared with environmental measures aimed at the industrial and service sector. This calculation methodology can calculate the EF of residential zone-level in a region to meet the measurement scale.

The EF indicator comprises the following components, which are linked to land use planning. These components are referred from the methodology developed in an earlier study [2].

1) Farmland needed to grow crops for food and feed (Farmland footprint)

2) Grazing land needed to graze animals for meat and milk

(Grazing land footprint)

3) Forestland needed to obtain material for use in paper production

(Forestland footprint).

4) Built-up land needed to conduct urban activities (Built-up land footprint)

5) Forestland needed to absorb $\mathrm{CO}_{2}$ from fossil fuels for household and private transport use (Energy footprint)

Table 2 presents the EF indicator value calculation method. Fishing grounds are excluded because the system particularly addresses the introduction into urban and regional planning.

There is a "global hectare (gha)" that is virtual land "1 hectare" considering the average productivity of land and water area on the earth. This unit is effective for macro analyses such as an international comparison of EF. The case study does not use the "global hectare" because the system basically is domestic trading.

"Ecological Footprint Standards 2009" were released by Global Footprint Network consisting of experts in EF on September 2009 [19]. This report broadly defines the standard of methodology for calculating EF. Adaptation to "Ecological Footprint Standards 2009" must be explored in future works for implementing systems in many countries.

Ujihara et al. [20] is developing EF calculation package at local government scale available for cap and trade system. 
Table 2: $\quad$ Method of EF indicator value calculation.

\begin{tabular}{|c|c|c|c|c|}
\hline \multicolumn{3}{|c|}{$\begin{array}{l}\text { Components } \\
\text { in the EF indicator }\end{array}$} & Formulas for calculation & Parameters \\
\hline 1) & Farmland & $E F_{\text {food }}^{k}$ & \multirow{3}{*}{$\begin{array}{c}F_{j}^{k}=\sum_{n=1}^{10} p_{n}{ }^{k} \cdot f_{n j} \\
E F_{\substack{\text { food feed } \\
\text { and grazing land }}}^{k}=\sum_{j=1}^{14} \frac{F_{j}^{k}}{\alpha_{j}}\end{array}$} & \multirow{3}{*}{$\begin{array}{l}F_{j}{ }^{k}: \text { Consumption of crop } j \\
\quad \text { in area } k(\mathrm{t}) \\
p_{n}{ }^{k}: \text { Population of age backet } n \\
\quad \text { in area } k \text { (person) } \\
f_{n j}: \text { Consumption of crop } j \text { in age } \\
\quad \text { bracket } n \text { (t/person) } \\
\alpha_{j}: \text { Land productivity of crop } j \text { (t/ha) }\end{array}$} \\
\hline & & Feed & & \\
\hline 2) & \multicolumn{2}{|c|}{ Grazing land footprint } & & \\
\hline & \multicolumn{2}{|c|}{$\begin{array}{l}\text { Forestland footprint } \\
\text { (paper) }\end{array}$} & $E F_{\text {paper }}^{k}=\frac{p_{n}^{k}}{p}$ & $\begin{aligned} w_{m} & : \text { Wood pulp and chip demanded } \\
& \text { in japan of each destination for } \\
& \text { import } m\left(\mathrm{~m}^{3}\right) \\
\beta_{m} & \text { : Growing stock amount of forest } \\
& \text { of each destination for import } \\
& m\left(\mathrm{~m}^{3} / \mathrm{ha}\right) \\
p: & \text { Population in Japan (person) } \\
r: & \text { Rate of household consumption }(\%)\end{aligned}$ \\
\hline 4) & \multicolumn{2}{|c|}{ Built-up land footprint } & $E F_{\text {built -up land }}^{k}=\sum_{i=1}^{3} b_{i}$ & $\begin{array}{l}b_{i}{ }^{k}: \text { Built-up of land use } i \\
\quad \text { in area } k \text { (ha) }\end{array}$ \\
\hline \multirow[t]{2}{*}{ 5) } & \multirow[t]{2}{*}{$\begin{array}{l}\text { Energy } \\
\text { footprint }\end{array}$} & Household & $E F_{\text {household }}^{k}=\sum_{i=1} \sum_{j=1} C_{i j}^{k} / r$ & $\begin{array}{c}C_{i j}{ }^{k}: \mathrm{CO}_{2} \text { emissions, type } i \\
\text { of houses, and size } j \text { of } \\
\text { households in area } k \text { (ton) } \\
r: \text { Absorption efficiency of } \mathrm{CO}_{2} \\
\quad\left(\mathrm{t}-\mathrm{CO}_{2} / \text { ha) }\right.\end{array}$ \\
\hline & & $\begin{array}{c}\text { Private } \\
\text { transportation }\end{array}$ & $E F_{\text {transport }}^{k}=p^{k} \cdot C^{k} \cdot k_{c} / r$ & $\begin{array}{l}C^{k}: \text { Automobile fuel consumption } \\
\quad \text { in area } k(\mathrm{CC} / \text { person }) \\
k_{c}: \text { Conversion factor }\end{array}$ \\
\hline
\end{tabular}

\subsubsection{Target regions}

An interregional cap and trade system using EF assumes trading of an entire country. Because of this, it is necessary to select widely various target regions covering diversified local governments across the country to the greatest extent possible. This case study selects the following regions in Japan with different environmental balance such as a small city and big city. Figure 3 presents target region locations. The environmental load excess ratios of target regions are calculated based on the EF value associated with residents' consumption, with reference to Table 2. However, the calculation methodology of each region differs slightly because of data limitations.

The environmental load excess ratio for all of Japan is 2.67 times. In other words, this case study assumes 2.67 times as the initial cap.

Tsuyama city in Okayama Prefecture (population: ca. 110,000): Tsuyama is a local city in intermediate and mountainous areas in western Japan. Although this city serves as a central city in northern Okayama Prefecture, it has a great deal of natural environmental areas such as rural and mountain areas. Tsuyama city is 


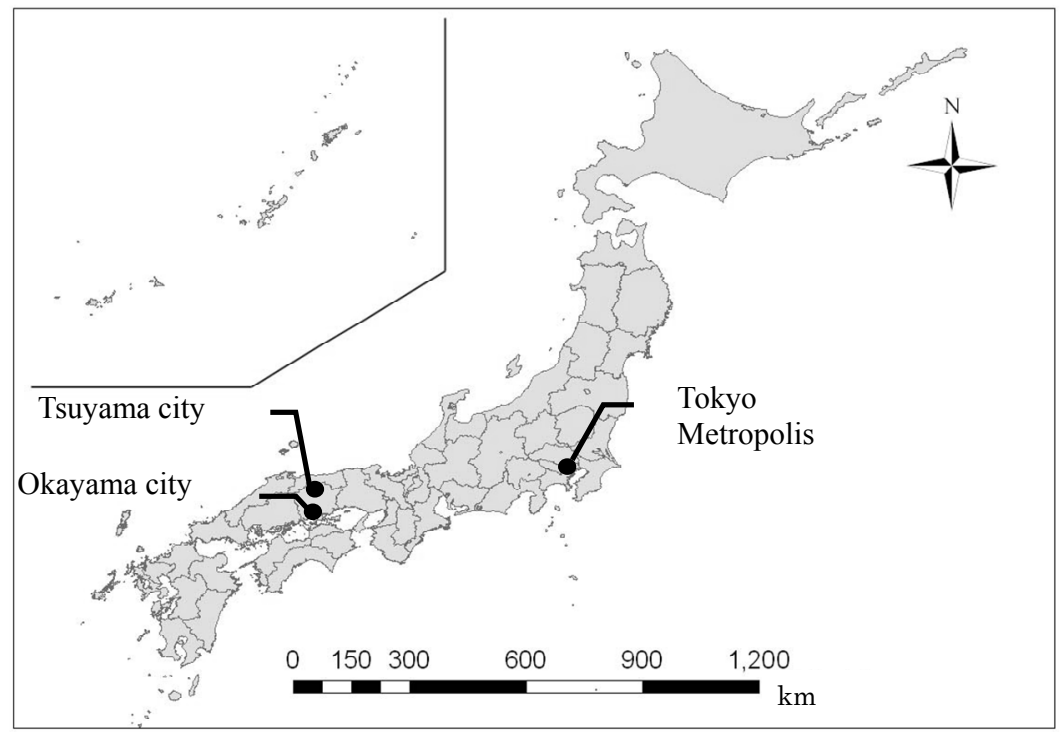

Figure 3: $\quad$ Locations of target regions.

defined as an environmentally burdened region because its environmental load excess ratio is 1.4 times.

Okayama city in Okayama Prefecture (population: ca. 670,000): Okayama city is a local central city in western Japan. This city has urban functions in its role as a business center of Okayama Prefecture. Okayama city is defined as an environmentally dependent region because the environmental load excess ratio is 13.5 times.

Tokyo Metropolis (population: ca. 13,000,000): The Tokyo Metropolis is the national capital. It is the center of economy and industry in Japan. The Tokyo Metropolis is defined as an environmentally dependent region because its environmental load excess ratio is 75.2 times.

\subsubsection{Setting of trading prices}

Land-rent-based trading prices: when trading of a footprint is implemented, dependency of land use can be converted into a trading price using the land rent. In fact, this method is marked by the ability to calculate trading prices based on interdependence of land resources. The following is the formula used for calculation.

$$
\begin{aligned}
& E L=E F-\alpha \cdot E C \\
& E P_{\text {rent }}=L R \cdot E L
\end{aligned}
$$

$\alpha$ : Cap (times)

$E P_{\text {rent }}$ : Trading price of environmentally dependent (burden) amount (euro/year)

$L R$ : Land rent per hectare (euro/year)

$E L$ : Environmental dependence (burden) amount (ha/year) 
The land rent is estimated easily by multiplying the land price by the social discount rate (0.04). Furthermore, the land price per hectare is the average value of forestland in Japan [21]. This price includes no value of the timber growing as trees on the land (1 euro equals 129.6 yen as of November 30, 2009) [22].

$\mathrm{CO}_{2}$ trading-price-based trading price: This is a method to calculate the trading price using existing $\mathrm{CO}_{2}$ trading prices. This method uses the $\mathrm{CO}_{2}$ trading price of EU-ETS, which has been implemented on a maximum scale in the EU because the trading price of EU-ETS affects other trading markets as a reference price. This case study adopts the $\mathrm{CO}_{2}$ trading price of EU-ETS as an alternative value for the trading footprint. The following is the formula used for calculation.

$$
\begin{aligned}
& P_{\mathrm{CO}_{2}}=p \cdot r_{\mathrm{CO} 2} \\
& E P_{\mathrm{CO}_{2}}=P_{\mathrm{CO}_{2}} \cdot E L
\end{aligned}
$$

$P_{\mathrm{CO} 2}$ : Trading price for $\mathrm{CO}_{2}$ absorption per hectare (euro/year)

$p$ : Existing $\mathrm{CO}_{2}$ trading price (euro/t- $\mathrm{CO}_{2}$ )

$r_{\mathrm{CO} 2}: \mathrm{CO}_{2}$ absorption efficiency of forest area ( $\mathrm{t}-\mathrm{CO}_{2} /$ ha $\bullet$ year)

$E P_{\mathrm{CO} 2}$ : Trading price for $\mathrm{CO}_{2}$ absorption to environmental dependence (burden) amount (euro/year)

This $\mathrm{CO}_{2}$ trading price of EU-ETS uses 13.54 euro $/ \mathrm{t}-\mathrm{CO}_{2}$, the closing average of November 2009 [23].

In addition to the forestland footprint, the EF includes farmland, the Grazing land footprint, and so on. The estimates include these components in trading price as equivalence of forestland. It is necessary to consider the value of different land use in the future.

\subsection{Association between trading price and cost of implementing measures aimed at improvement of the environmental balance}

The case study assumes that the trading price of Tsuyama city, obtained as the burden amount of environmental load, is used as financial resources for urban and regional planning toward improvement of the environmental balance.

\subsubsection{Settings of scenarios}

These scenarios are aimed at urban compaction and land recycling with reform of a regional form. Table 3 presents settings of scenarios and its estimated costs. One key point is the degree to which the local government side bears the implementation cost. The scenario budget cost to use low-use and unused lands as natural land use from initial investment (with the exception of cost of land acquisition) to maintenance. The case of the abandoned cultivated lands is similar. However, urban compaction requires incentives for promoting residences in city centers. For this reason, this scenario budgets the cost of lowuse and unused lands acquisition in the city center as an incentive for promoting residence in the city center, in addition to nature regeneration in suburban areas. 
Table 3: $\quad$ Settings of scenarios and the assumed costs.

\begin{tabular}{|c|c|c|c|}
\hline \multicolumn{2}{|r|}{ Scenarios } & Settings & Assumed costs \\
\hline \multirow{2}{*}{$\begin{array}{l}\text { Land } \\
\text { recycling }\end{array}$} & $\begin{array}{l}\text { Utilization of } \\
\text { less-used and } \\
\text { unused lands }\end{array}$ & $\begin{array}{l}\text { Scenario for converting less-used } \\
\text { and unused lands (Area: ca. } 180 \\
\text { ha) in suburbs into natural land } \\
\text { use }\end{array}$ & $\begin{array}{l}\text { Costs of reforestation*: } \\
\text { Cost of afforestation } \\
\text { Cost of maintenance }\end{array}$ \\
\hline & $\begin{array}{l}\text { Utilization of } \\
\text { abandoned } \\
\text { cultivated lands }\end{array}$ & $\begin{array}{l}\text { Scenario for converting } \\
\text { abandoned cultivated lands } \\
\text { (Area: ca. } 480 \text { ha) in suburbs into } \\
\text { natural land use }\end{array}$ & $\begin{array}{l}\text { Costs of farmland } \\
\text { Regeneration*: } \\
\text { Cost of land-clearing } \\
\text { Cost of seedling and fertilizer } \\
\text { Cost of Maintenance } \\
\text { *Excluding labor costs }\end{array}$ \\
\hline \multicolumn{2}{|c|}{ Urban compaction } & $\begin{array}{l}\text { Urban compaction is set as a } \\
\text { scenario for promoting } \\
\text { development of low-use and } \\
\text { unused lands in the city center } \\
\text { (acceptance potential: } 2,066 \\
\text { people), with constraint of } \\
\text { development in suburban areas. }\end{array}$ & $\begin{array}{l}\text { Cost of land acquisition in the } \\
\text { city center } \\
\text { Costs of the above-described } \\
\text { forests and farmlands } \\
\text { regeneration }\end{array}$ \\
\hline
\end{tabular}

\subsubsection{Calculation method of cost of implementing measures}

The project term of each scenario is assumed conveniently as a decade. Those projects progress in stages. The evaluation period of the scenario is 50 years, including the project period. The total cost related to the implementation of scenarios is converted into present value using a social discount rate $(0.04)$.

What land use (farmland, forestland, and so on) should be converted is determined by location conditions and the purpose of the user if low-used and unused lands in rural areas and mountain areas are converted into a nature land use. This case study broadly assumes that the conversion ratios are 70 percent for farmland and 30 percent for forest land, considering location conditions (rural areas and mountain areas) using GIS.

\section{Results}

\subsection{Trading price of target regions}

Figure 4 presents results of trading prices of target regions based on the initial cap. For cap " 2.67 ", for example, Tsuyama city (environmentally burdened region) has 4 million euros per year as the burden amount for an environmental load. In contrast, Okayama city (Environmentally dependent region) is subjected to 57 million euros per year as the dependence amount of the environmental load. 


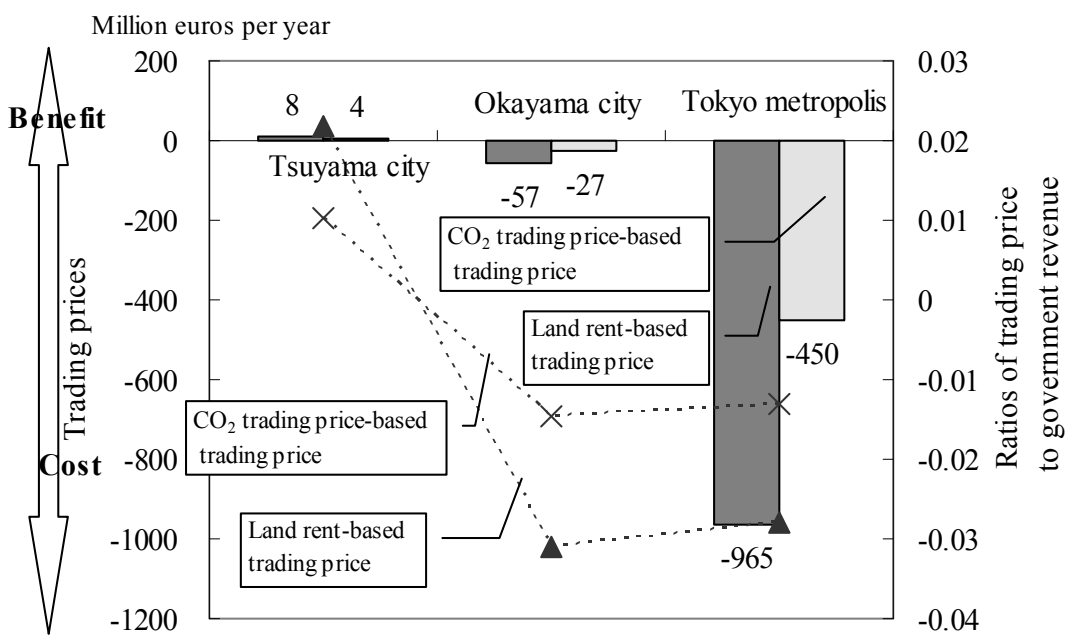

Figure 4: Trading prices and the ratios of them to government revenue.

Tsuyama city can also expend a trading price obtained as the burden amount of environmental load for urban and regional planning toward improvement of the environmental balance. For a trading price of " 4 million euros", this is equivalent to 8.7 percent of civil engineering expenses in Tsuyama city, including urban planning [24].

Figure 4 shows also the ratios of the trading price to the target region's revenues [24]. For land rent-based trading prices, those ratios are 2.2 percent in Tsuyama city as the beneficiary, 3.1 percent in Okayama city and 2.8 percent in Tokyo Metropolis as the payment. Environmentally dependent regions will pay about 3.0 percent to revenue as the trading price if an interregional cap and trade system using EF is introduced.

\subsection{Association between trading prices and implementation costs of each scenario}

As Figure 5 shows, for land rent-based trading prices, the total implementation costs of each scenario are lower than the trading price during the evaluation period. In the case of $\mathrm{CO}_{2}$ trading price-based trading prices, only total implementation costs of the utilization scenario of abandoned cultivated lands slightly exceed the trading price.

In this case study, total implementation costs of each scenario include initial investment and maintenance costs as implementation costs of each scenario. In addition, utilization scenarios of abandoned cultivated lands are targeted at all abandoned cultivated lands in the target region. 


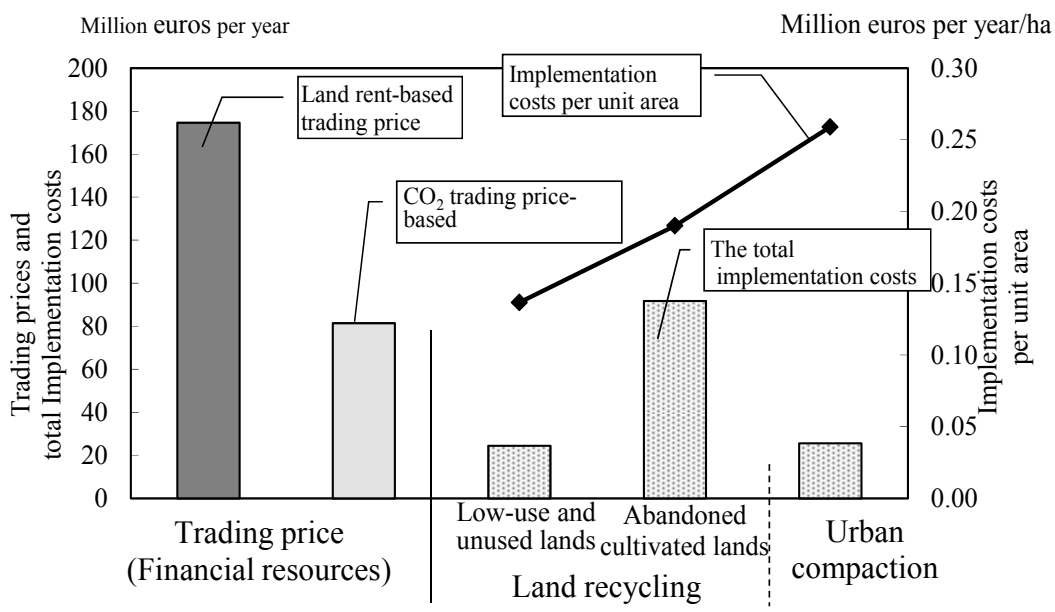

Figure 5: Trading prices and total cost related to the implementation of scenarios.(Conversion into present value).

It is necessary to discuss how far implementation costs should be covered, with a financial resources scale obtained using this system in mind. Furthermore, as noted from Table 3, each scenario assumes costly measures that are of a drastically reformed regional form. In other words, even if large-scale measures are implemented, trading prices related with an interregional cap and trade system using EF are highly influential on financial resources for urban and regional planning. This case study demonstrated the possibility that implementation costs are covered by the trading price.

Figure 6 shows a newly obtainable trading price by improving environmental balance in regions. Regarding the trading price per unit area associated with measures, the effect of the urban compaction scenario is highest in each scenario. This results from the realization of energy-efficient living spaces (from house in suburban areas to apartment in city center) and low traffic environmental loads by promoting residence in the city center, along with utilization of low-use and unused lands in suburban areas, while land recycling for land for the principal purpose of utilization of the land itself.

As Figures 5 and 6 show, the newly obtainable trading price is $2-6$ percent of the implementation cost. The generation of new financial resources will create incentives to implementation of measures in the region. 
1) For land rent-based trading prices

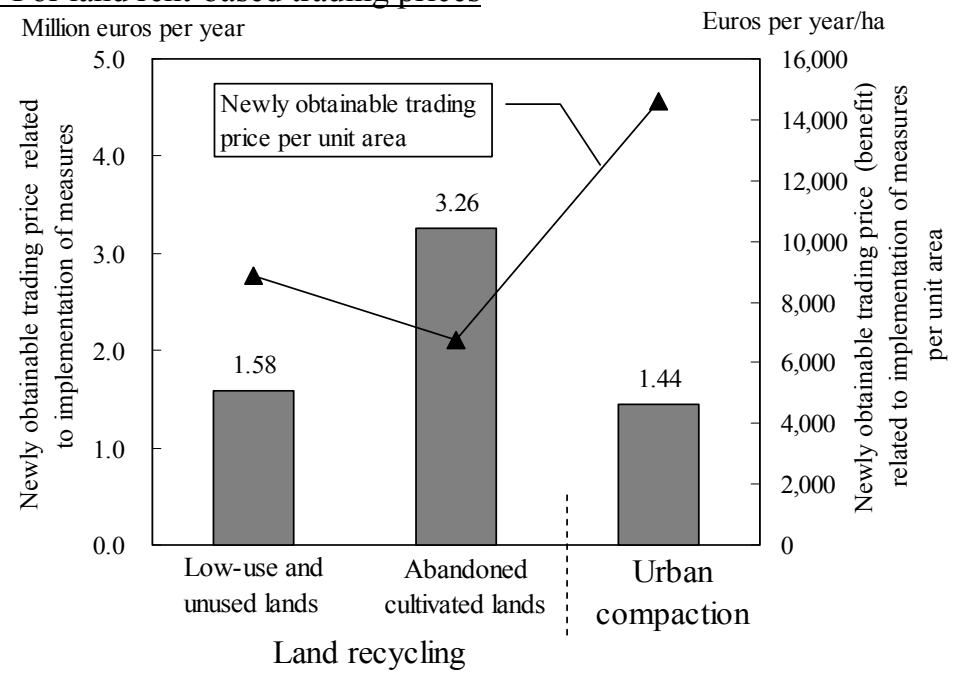

2) For the $\mathrm{CO}_{2}$ trading price-based trading price

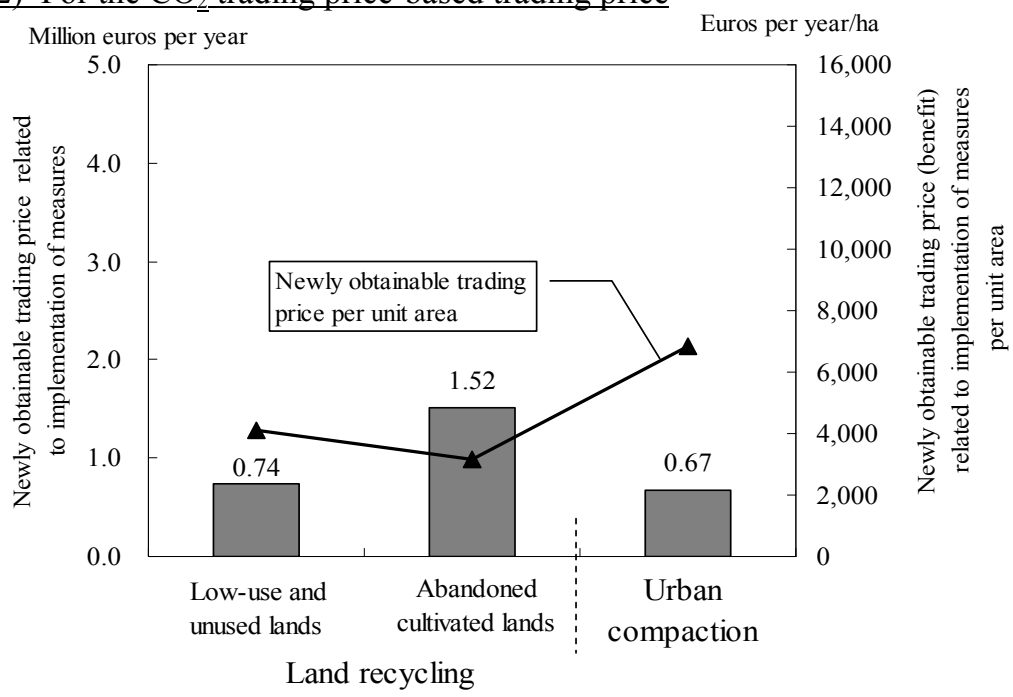

Figure 6: Newly obtainable trading price by improvement of the regional environmental balance (Conversion into present value).

\section{Discussion and conclusions}

An interregional cap and trade system using EF developed by Ujihara et al. [3] is expected to become an effective tool to promote voluntary measures intended for improvement of the environmental balance in the region. In fact, the system is discussed as one efficient tool for a growth strategy in the Panel on Infrastructure 
Development [1]. This is a breakthrough move that raises the feasibility of this system. Although a larger movement can take place at the national level, it is necessary to examine, for exploration of future prospects of this system, whether it becomes a structure that can contribute to improvement of the environmental balance from the viewpoint of financial resources for urban and regional planning. This study proposed a mechanism for securing financial resources based on an interregional cap and trade system using EF. Based on this mechanism, the study explored future prospects of the system to examine effects on financial resources for urban and regional planning. Results of those analyses show that trading prices related with interregional cap and trade systems using EF are highly influential for financial resources intended for urban and regional planning. The case study demonstrated the possibility that implementation costs are covered by the trading price, even if large-scale measures that drastically reform the regional structure are implemented. However, the mechanism for improving environmental balance aimed at the region side burdened with the expenses should be considered in the future. It is important to present a widely varied planning menu of considerations to regionalism, not only costly land-use measures but also inexpensive measures to promote the environmentally conscious behavior of residents.

\section{References}

[1] Ministry of Land, Infrastructure, Transport and Tourism, http://www.mlit .go.jp/policy/shingikai/s204_toshikeikakuseido01.html, 2010. (Accessed on August 30, 2010). (in Japane-se)

[2] Wackernagel, M., Rees, W. E., Our Ecological Footprint: Reducing Human Impact on the Earth. New Society Publishers, 1996. (Canada).

[3] Ujihara, T., Taniguchi, M., Matsunaka, R., Interregional cap \& trade program using ecological footprint: national land use planning for balanced environment. Journal of the City Planning Institute of Japan 43, pp.877-882, 2008. (in Japanese)

[4] Bicknell, K.B., Ball, R.J., Cullen, R., Bigsby, H.R, New methodology for the ecological footprint with an application to the New Zealand economy. Ecological Economics 27, pp.149-160, 1998.

[5] Ferng, J.-J., Using composition of land multiplier to estimate ecological footprint associated with production activity. Ecological Economics 37, pp.159-172, 2001.

[6] WWF, Living Planet Report. http://assets.panda.org/downloads/ living_planet_report.pdf, 2006 (accessed on August 20, 2010).

[7] Folke, C., Jansson, A., Larsson, J., Costanza, R., Ecosystem, Appropriation by cities. Amboi 26(3), pp.167-172, 1997.

[8] Barrett, J., Vallack, H., Jones, A., Haq, G., A Material Flow Analysis and Ecological Footprint of York. Stockholm Environment Institute, 2002.

[9] Taniguchi, M., Hirofumi, A., Shigekane, K., Prefectural balance sheet of the environment - study based on the ecological footprint -. Studies in Regional Science 34(1), pp.23-35, 2003. (in Japanese) 
[10] Best Foot Forward, City Limits A resource flow and ecological footprint analysis of Greater London, 2004.

[11] Bagliani, M., Galli, A., Niccolucci, V., Marchettini, N., Ecological footprint analysis applied to a sub-national area: The case of the Province of Siena (Italy). Journal of Environmental Management 86, pp.354-364, 2008.

[12] Barrett, J., Scott, A., An Ecological Footprint of Liverpool: Developing Sustainable Scenarios. Stockholm Environment Institute, 2001.

[13] James, N., Desai, P., One Planet Living in the Thames Gateway-A WWFUK One Million Sustainable Homes Campaign Report, WWF-UK, Surrey, UK, 2003.

[14] Kiyooka, T., Taniguchi, M., Matsunaka, R., Study of sustainability of local scale land-use based on the Ecological Footprint index. Journal of the City Planning Institute of Japan 40-3, pp.55-60, 2005. (in Japanese)

[15] Muñiz, I., Galindo, A., Urban form and the ecological footprint of commuting. The case of Barcelona, Ecological Economics 55, pp.499-514, 2005.

[16] Ujihara, T., Taniguchi, M., Matsunaka, R., Sustainability of city planning based on the ecological footprint indicator: Balance between environmental load and environmental capacity. Selected Papers Environmental Systems Research 36, pp.207-215, 2008. (in Japanese)

[17] Andersson, J.O., Lindroth, M., Ecologically unsustainable trade. Ecological Economics 37, 113-122, 2001.

[18] Ohl, B., Wolf, S., Anderson, W., A modest proposal: global rationalization of ecological footprint to eliminate ecological debt. Sustainability: Science, Practice, \& Policy 4(1), pp.5-16, 2008.

[19] Global Footprint Network, Ecological Footprint Standards 2009. http://www. footprintnet-work.org/images/uploads/Ecological_Footprint Standards_2009.pdf, 2009. (accessed on October 21, 2009).

[20] Ujihara, T., Furuichi, S., Shirato, S., Taniguchi, M., Evaluation for environmental balance of local government-scale based on the ecological footprint: By using practical calculation package "EF-Calc", Proceedings of $38^{\text {th }}$ annual meeting of environmental systems research, pp.245-251, 2010. (in Japanese)

[21] Japan Real Estate Institute, http://www.reinet.or.jp/, 2005. (accessed on February 30, 2008) (in Japanese)

[22] Yahoo Japan Finance, http://quote.yahoo.co.jp/, 2009. (accessed on November 30, 2009) (in Japanese)

[23] Point Carbon, http://www.pointcarbon.com/, 2009. (accessed on August 30, 2010)

[24] Ministry of Internal Affairs and Communications, http://www.soumu.go.jp /iken/zaisei/card-8.html, 2009. (accessed on April 30, 2009) (in Japanese) 